\author{
Abdelkarim S. Allal \\ Marie-Anne Bründler \\ Pascal Gervaz
}

\section{Differential expression of anti-apoptotic protein Bcl-2 in keratinizing versus non-keratinizing squamous cell carcinoma of the anus}

Accepted: 7 July 2004

Published online: 2 October 2004

(C) Springer-Verlag 2004

\begin{abstract}
Background: Histologically, tumors of the anal region are either keratinizing $(\mathrm{K})$ or non-keratinizing (NK) squamous cell carcinomas (SCCA). We hypothesized that these two variants might represent, not only morphologically, but also biologically, dissimilar malignancies. The present study was undertaken to compare the expression of apoptosisregulating proteins $\mathrm{Bcl}-2$ and $\mathrm{p} 53$ in $\mathrm{K}$ versus NK SCCA. Methods: We performed an immunohistochemical analysis on 98 pre-treatment biopsies of patients with anal canal cancers. Tissue sections were examined immunohistochemically for expression of proteins Bcl-2 (clone 124, DAKO, 1:100) and p53 (clone DO7, DAKO, 1:200). Expression of p53 and Bcl-2 was considered positive when $>5 \%$ of tumor cells were stained. Tumor histology was correlated with protein expression as well as with other clinical variables. Results: There were $64 \mathrm{NK}$ and $34 \mathrm{~K} \mathrm{SCC}$. The proportion of $\mathrm{Bcl}-2$ positive tumors
\end{abstract}

was statistically higher in NK carcinomas (51.5 vs. $23.5 \%, p=0.009)$. In addition, women were more likely than men to present with NK carcinomas (71 vs. $45 \%, p=0.03$ ) as well as with $\mathrm{Bcl}-2$ positive tumors (47 vs. $29 \%, p=0.05)$. The more distal the tumor is (anal margin), the more frequently the keratinizing subtype is observed (87 vs. $23 \%, p=0.0002$ ). By contrast, there was no correlation between $\mathrm{p} 53$ and tumor histology ( $p=0.83)$. Conclusions: Our data demonstrate that non-keratinizing and keratinizing SCCA differ in their Bcl-2 expression. In addition, significant differences were observed in the distribution of these two histological subtypes according to gender and tumor sublocation. These findings may indicate possible differences in the carcinogenesis process of these two histological subtypes.

Keywords Anal cancer . Immunohistochemistry • Keratinizing $\cdot$ P53 $\cdot$ Bcl-2

\section{Introduction}

Considerable confusion in the literature arises from the use of different anatomic definitions of the anal area: anal cancer may arise from the anal canal or from the anal margin. Eighty-five percent of anal cancers occur in the anal canal and $15 \%$ in the anal margin [1]. The problem with this anatomical distribution is of more than academic interest, since anal margin tumors behave like skin cancer and may differ in their oncological outcomes $[2,3]$. Sim- ilarly, confusion arises with regard to the histological classification of anal canal cancers. Tumors arising within the transitional zone were referred as junctional, basaloid or cloacogenic. These terms have been abandoned and, histologically, tumors of the anal canal are now referred as either keratinizing $(\mathrm{K})$ or non-keratinizing $(\mathrm{NK})$ squamous cell carcinomas (SCCA) $[4,5]$.

By recognizing that non-keratinizing and keratinizing SCCA have a similar clinical outcome, it is generally assumed that both variants are biologically identical. 
The molecular biology of anal cancer is poorly understood, but epidemiological studies have clearly demonstrated that infection with high-risk human papillomavirus (hrHPV) is responsible for the majority of cases [6, 7]. Recently, Frisch et al. reported increasing hrHPV positivity in tumors located in the proximal portion of the anal canal, and keratinizing tumors were less likely to be hrHPV positive than non-keratinizing tumors $(\mathrm{OR}=9.3$ ) [8]. Moreover, the disruption of the p53 tumor suppressor pathway by human papillomavirus (HPV) E6 oncoprotein is considered a key event in anal and cervical carcinogenesis [9]. Others key players in regulating the apoptotic pathway are the Bcl-2 genes family [10]. Expression of the Bcl-2 gene has been shown to effectively confer resistance to programmed cell death in a variety of tumors, and a highly significant association between hrHPV infection and Bcl-2 overexpression has been described [11].

Since keratinization appears to be less associated with hrHPV infection, we hypothesized that keratinizing and non-keratinizing SCCA may differ biologically in their expression of some apoptosis-regulating proteins. This study was undertaken to characterize the expression of Bcl-2 and p53 in SCCA, according to the histological subtypes as recently defined: keratinizing versus nonkeratinizing.

\section{Materials and methods}

Patients

Patient selection for this study was based on the availability of adequate pre-treatment paraffin blocks. From January 1976 to November 1998, we identified 98 adequately embedded biopsy specimens. All tumors were classified according to the 1997 staging system of the Union Internationale Contre le Cancer (UICC, 1997). Patients' characteristics are presented in Table 1. The following clinico-pathological parameters were considered for analysis: demographics (age, gender); location of the tumor (anal canal vs. anal margin vs. overlapping); histological grade (keratinizing vs. non-keratinizing); and tumor stage according to the tumor-nodemetastasis (TNM) classification.

Pathology and immunohistochemistry

An experienced pathologist (M.-A. B.) reviewed all pre-treatment biopsies. Tumors were classified as keratinizing or non-keratinizing SCCA according to one of the recommendations of the WHO criteria [12]. Thus, tumors previously considered junctional, basaloid or cloacogenic were defined as non-keratinizing SCCA except those presenting with keratinizing features. For the immunohistochemistry, formalin-fixed and paraffin-embedded tissue blocks were cut at $4 \mu \mathrm{m}$ and mounted on silane-coated glass slides. Immunohistochemical stains were performed applying a standard $\mathrm{ABC}$ technique for Bcl-2 (clone 124, DAKO, 1:100) and p53 (clone DO7, DAKO, 1:200). Heat-induced antigen retrieval was done using a microwave oven $(600 \mathrm{~W}, 3 \times 5 \mathrm{~min})$ and citrate buffer (0.01 M, pH 6) for Bcl-2, while p53 was retrieved by using a pressure cooker (3 min). After cooling down and washing, slides were incubated with the primary antibody for $30 \mathrm{~min}$ at room temperature. Following another washing cycle, slides were incu-
Table 1 Patients' clinico-pathological characteristics $(n=98)$

\begin{tabular}{lc}
\hline Characteristic & Number $(\%)$ \\
\hline Median age in years; range & $68 ; 41-86$ \\
Male/female & $22 / 76$ \\
Tumor location & $72(73.5)$ \\
Anal canal & $8(8.1)$ \\
Anal margin & $18(18.4)$ \\
Both (overlapping) & \\
Tumor histology & $34(34.7)$ \\
Keratinizing & $64(65.3)$ \\
Non-keratinizing & \\
Tumor stage (UICC 1997) & $60(61.2)$ \\
T1-T2 & $38(38.8)$ \\
T3-T4 & $74(75.5)$ \\
N0 & $22(22.5)$ \\
N1-N3 & $2(2)$ \\
N $x$ & \\
P53 expression & $56(57.1)$ \\
Positive & $42(42.9)$ \\
Negative & \\
Bcl-2 expression & $41(41.8)$ \\
Positive & $57(58.2)$ \\
Negative &
\end{tabular}

bated with biotinylated secondary antibody (biotinylated rabbit anti-mouse Immunoglobulins, F( $\left.\mathrm{ab}^{\prime}\right) 2$, DAKO E0413) for $30 \mathrm{~min}$, and after washing with a streptavidin-biotinylated-HRP complex (StreptABComplexes, DAKO K0377). Slides were washed thoroughly, and then incubated with diaminobenzidine used for visualization.

Evaluation of immunohistochemical stains was done by one of the authors (M.-A. B.). Results were assessed using a semi-quantitative score based on the estimated percentage of positive cells: $0=0 \% ; 1=<5 \% ; 2=5-50 \% ; 3=50-90 \%$; and $4=>90 \%$. Tumors were then classified into two groups according to the level of expression of the protein considered (low/negative $=$ negative or high/positive $=$ positive) . Expression of $\mathrm{p} 53$ and $\mathrm{Bcl}-2$ proteins was considered positive if $>5 \%$ of the malignant cells were stained (score $2-4$ ). Staining in $<5 \%$ of tumor cells (score $0-1$ ) was considered to be negative expression.

\section{Statistical analysis}

Group comparisons were made using the chi-square or Fisher's exact test (two-sided) for categorical variables, and the MannWhitney $U$ test for continuous variables. Any $p$ values less than or equal to 0.05 were considered statistically significant. All analyses were performed with StatView V 5.0.1 software.

\section{Results}

\section{Immunostaining}

Regarding the expression of Bcl-2, 40 tumors showed no staining, and 17 tumors demonstrated staining in less than $5 \%$ of cells. Thus, Bcl-2 expression was considered negative in 57 patients $(58 \%)$ and positive in 41 patients (42\%). For the expression of p53, 42 tumors had a negative expression $(43 \%)$ and $56(57 \%)$ a positive expression. 
Table 2 Comparison of keratinizing ( $n=34)$ versus non-keratinizing $(n=64)$ squamous cell carcinomas (SCCA)

\begin{tabular}{llll}
\hline & $\begin{array}{l}\text { Keratinizing } \\
(\%)\end{array}$ & $\begin{array}{l}\text { Non-keratinizing } \\
(\%)\end{array}$ & $p$ value \\
\hline Age, median; range & $68 ; 41-85$ & $67 ; 41-86$ & 0.2 \\
$\begin{array}{l}\text { Gender } \\
\text { Male }\end{array}$ & $12(35)$ & $10(16)$ & 0.03 \\
Female & $22(65)$ & $54(84)$ & \\
$\begin{array}{l}\text { Tumor location } \\
\text { Anal canal }\end{array}$ & $19(56)$ & $53(82.5)$ & 0.0002 \\
Anal canal + margin & $8(24)$ & $10(16)$ & \\
Anal margin & $7(20)$ & $1(1.5)$ & \\
Tumor stage & $20(59)$ & $40(62.5)$ & 0.7 \\
T1-T2 & $14(41)$ & $24(37.5)$ & \\
T3-T4 & $20(59)$ & $36(56)$ & 0.83 \\
P53 expression & $14(41)$ & $28(44)$ & \\
Positive & & & \\
Negative & $8(23.5)$ & $33(51.5)$ & \\
Bcl-2 expression & $26(76.5)$ & $31(48.5)$ & \\
Positive & & & \\
Negative & &
\end{tabular}

Clinico-patho-biological associations

The relationships between the clinico-biological tumor characteristics and the histological subtype (keratinizing vs. non-keratinizing SCCA) are summarized in Table 2. While no differences existed according to the median age, female patients presented a significantly higher proportion of the non-keratinizing subtype than male patients (71 vs. $45 \%, p=0.03$ ). Moreover, there was a highly significant difference in the distribution of the two histological subtypes according to the tumor sublocation $(p=0.0002)$. The more distal the tumor is (anal margin) the more the keratinizing subtype is observed (87 vs. $23 \%$ ).

Positive expression of Bcl-2 was observed in a significantly higher proportion of non-keratinizing tumors than the keratinizing subtype (51.5 vs. $23.5, p=0.009)$. On the other hand, no significant association was observed between p53 expression and the histological subtype $(p=0.83)$.

Positive expression of Bcl-2 was more frequent in females than in male patients ( 47 vs. $29, p=0.05$ ). This result is in accordance with the fact that non-keratinizing tumors are more prevalent in female than in male patients.

\section{Discussion}

We report a relatively large series of patients presenting with SCCA who were managed in a one institution; the male/female ratio (1/3), the median age at diagnosis (68 years) are in accordance with the epidemiology of these tumors prior to the HIV era [13]. Similarly, the distribution of tumors within the anus (ration margin/canal $=1 / 4$ ), as well as the higher proportion of non-keratinizing tumors are consistent with larger previously published series in Europe [14]. Our data indicate that Bcl-2 and p53 proteins are expressed in $42 \%$ and $57 \%$ of SCCA respectively. Bcl-2 positive expression was significantly associated with non-keratinizing SCCA. In addition, women presented with a higher proportion of Bcl-2-positive tumors. By contrast, p53 protein expression was not significantly related to tumor histology.

The sequence of epithelial zones within the anal canal is anal transitional zone (ATZ), non-keratinized squamous epithelium, and squamous epithelium [15]. In the most recent classification of anal cancers, it has been recommended that the generic term anal squamous cell carcinoma be used for all previous subtypes of anal cancers, namely basaloid, transitional, large-cell keratinizing, and large-cell non-keratinizing [12]. This simplification, however, does not signify that all SCCA are similar,; our data clearly indicate that the higher the tumor is located within the anal region, the higher the proportion of tumor expressing the anti-apoptotic protein Bcl-2.

Obviously, larger series are needed to determine whether these differences may have an impact on the prognosis or on the response to chemoradiation protocols. What can be inferred, however, from the abundant literature regarding SCC of the uterine cervix, is that:

1. Bcl-2 overexpression is a risk factor for the progression of HPV-related lesions [16]

2. Bcl-2 expression is associated with a poor response to chemotherapy [17]

3. Bcl-2 is a strong independent prognostic parameter for overall survival [18]

Whether these data on uterine cervix carcinoma can be translated to SCCA remains hypothetical. We previously correlated the expression of various apoptosis-regulating proteins with the response to chemoradiation in patients with anal cancer [19]. Surprisingly, the lack of Bcl-2 expression was significantly correlated with poorer diseasefree survival. Conflicting data from the literature demonstrate that tumor response (or resistance) to chemoradiation is a complicated process that is unlikely to be controlled by a single molecule, or even by a single protein family. However, our results strongly suggest that, from a biological standpoint, tumors originating from the supradentate anal canal may represent a distinct entity, characterized by an increased expression of anti-apoptotic protein Bcl-2.

In summary, our data demonstrate that non-keratinizing and keratinizing SCCA differ in their expression of the anti-apoptotic protein $\mathrm{Bcl}-2$. This finding should alert clinicians and pathologists to the risks related to oversimplification in the histological classification of these tumors. Indeed, these results may indicate possible differences in the carcinogenesis process of these two histological subtypes. Thus, we recommend for future clinical studies that the histopathological terminology of SCCA should still consider the degree of keratinization in order to identify potential differences in prognosis. 


\section{References}

1. Ryan DP, Compton C, Mayer RJ (2000) Carcinoma of the anal canal. N Engl J Med 342:792-800

2. Fuchshuber P, Rodriguez-Bigas M, Weber T, Petrelli NJ (1997) Anal canal and perianal epidermoid cancers. J Am Coll Surg 185:494-505

3. Nigro ND (1996) Neoplasms of the anus and anal canal. In: Condon RE (ed) The colon, 4th edn. Saunders, Philadelphia, pp 355-367

4. Ryan DP, Mayer RJ (2000) Anal carcinoma: histology, staging, epidemiology, treatment. Curr Opin Oncol $12: 345-352$

5. Gervaz P, Allal A, Villiger P, Buhler L, Morel P (2003) Squamous cell carcinoma of the anus. Another sexually transmitted disease. Swiss Med Wkly 133:353-359

6. Frisch M, Glimelius B, van den Brule AJC, Wohlfart J, Meijer CJ et al (1997) Sexually transmitted infection as a cause of anal cancer. N Engl J Med 337:1350-1358

7. Tilston P (1997) Anal human papillomavirus and anal cancer. J Clin Pathol 50:625

8. Frisch M, Fenger C, van den Brule AJ, Sorensen P, Meijer CJ et al (1999) Variants of squamous cell carcinoma of the anal canal and perianal skin and their relation to human papillomaviruses. Cancer Res 59:753-757
9. Grace VM, Shalini JV, Lekha TT, Devaraj SN, Devaraj H (2003) Cooverexpression of p53 and bcl-2 proteins in HPV-induced squamous cell carcinoma of the uterine cervix. Gynecol Oncol 91:51-58

10. Tjalma WA, Weyler JJ, Bogers JJ, Pollefliet C, Baay M et al (2001) The importance of biological factors (bcl-2, bax, p53, PCNA, MI, HPV and angiogenesis) in invasive cervical cancer. Eur J Obstet Gynecol Reprod Biol 97:223-230

11. Sultana H, Kigawa J, Kanamori Y, Itamochi H, Oishi T et al (2003) Chemosensitivity and p53-Bax pathway-mediated apoptosis in patients with uterine cervical cancer. Ann Oncol 14:214-219

12. Fenger C, Frisch M, Marti MC, Parc R (2000) Tumours of the anal canal. In: Hamilton SR, Aaltonen LA (eds) World Health Organization classification of tumours: pathology and genetics of tumours of the digestive system. IARC, Lyon, pp 146-155

13. Myerson RJ, Karnell LH, Menck HR (1997) The national cancer data base report on carcinoma of the anus. Cancer 80:805-815
14. Schlienger M, Krzisch C, Pene F, Marin JL, Gindrey-Vie B et al (1989) Epidermoid carcinoma of the anal canal: treatment results and prognostic variables in a series of 242 cases. Int J Radiat Oncol Biol Phys 17:1141-1151

15. Fenger $C$ (2002) Prognostic factors in anal carcinoma. Pathology 34:573-578

16. Kurvinen K, Syrjanen K, Syrjanen S (1996) P53 and bcl-2 proteins as prognostic markers in human papillomavirus-associated cervical lesions. J Clin Oncol 14:2120-2130

17. Crawford RA, Caldwell C, Iles RK, Lowe D, Shepherd JH et al (1998) Prognostic significance of the bcl-2 apoptotic family of proteins in primary and recurrent cervical cancer. Br J Cancer 78:210-214

18. Tjalma W, Weyler J, Goovaerts G, De Pooter C, Van Marck E et al (1997) Prognostic value of bcl-2 expression in patients with operable carcinoma of the uterine cervix. J Clin Pathol 50:33-36

19. Allal AS, Waelchli L, Bründler M-A (2002) Prognostic value of apoptosisregulating proteins in anal carcinoma patients. ESTRO 21st Meeting, Praha 17-21 September 2002. Radiother Oncol 64 [Suppl 1]:152 